\title{
EDUCAÇÃO AMBIENTAL CRÍTICA E A PEDAGOGIA HISTÓRICO-CRÍTICA: REFLEXÕES A PARTIR DO GRUPO DE PESQUISA EM EDUCAÇÃO \\ AMBIENTAL - GPEA/UNESP
}

Daniele Cristina de Souza ${ }^{1}$

\begin{abstract}
Resumo
Frente à preocupação com a inserção da educação ambiental crítica, na escola, é que buscamos contributos teórico-metodológicos na pedagogia-histórico crítica. Nesse sentido, o presente artigo abordará reflexões teóricas que nascem dentro do Grupo de Pesquisa, em Educação Ambiental da Unesp-Bauru, e que foram, inicialmente, apresentadas durante o I Simpósio Materialismo Histórico Dialético e Pesquisa em Ensino de Ciências e Educação Ambiental. Assim, abordamos a questão do conteúdo da educação ambiental crítica a partir da concepção de currículo da pedagogia histórico crítica. Apesar da questão do conteúdo e forma da Educação Ambiental estar presente desde suas origens, entendemos que ainda é ausente o debate aprofundado sobre qual deve ser o seu conteúdo no contexto escolar. Nesse sentido, assumir a inserção escolar da Educação Ambiental crítica enquanto atividade nuclear do currículo, a partir de conteúdos essenciais, é uma forma de superar suas limitações na teoria e na prática para a formação humana necessária a transformação social.
\end{abstract}

Palavras Chave: Conteúdos essenciais; Currículo; Temáticas ambientais; Humanização.

\section{Introdução}

As reflexões trazidas nesse artigo nascem a partir do estudo e pesquisas realizadas no Grupo de Pesquisa em Educação Ambiental - GPEA, ligado ao Programa de Pós-Graduação em Educação em Ciências, Unesp - Bauru, e que foram inicialmente compartilhadas durante o I Simpósio Materialismo Histórico Dialético e Pesquisa em Ensino de Ciências e Educação Ambiental em 2018.

O GPEA - UNESP, campus Bauru, desde 2007, tem se dedicado à construção teórica e prática em torno da educação ambiental crítica em diálogo, ou a partir da Pedagogia Histórico Crítica (SAVIANI, 2011). Nesse contexto, serão trazidas algumas reflexões decorrentes do grupo de pesquisa que, no momento, tem uma situação bastante particular, pois está constituído por ex-alunos da Unesp-Bauru, que estão espalhados por instituições de ensino superior, no Brasil, e cujas pesquisas têm se concentrado em seus campos de atuação mais específicos.

\footnotetext{
${ }^{1}$ Professora Adjunto no curso de Licenciatura em Educação do Campo, na Universidade Federal do Triângulo Mineiro, campus Uberaba - MG. E-mail: daniele.souza@uftm.edu.br $\underline{\text { http://orcid.org/0000-0002-0703-6124 }}$
} 
Assim, aqui são construídos sentidos das questões do grupo, em algumas dimensões com recortes próprios, mas sem perder de vista o que se propõe coletivamente.

Inicialmente, a delimitação sobre a questão do conteúdo da Educação Ambiental crítica se deu a partir dos resultados de um projeto de pesquisa que buscou investigar quais as fontes de informação que os professores utilizavam para trabalharem educação ambiental. Um destaque dos resultados, que chamou a atenção, é que os professores utilizavam os próprios materiais dos alunos, ou nem entendiam o que significava ter uma fonte de informação para trabalhar a educação ambiental (TOZONI-REIS et al., 2013). A partir dessa constatação, o grupo começou a pensar sobre a construção de processos de formação continuada e de recursos didáticos que contribuíssem para a inserção escolar da EA crítica. Assim surgiu a questão: qual deveria ser o conteúdo da EA escolar?

Nem tanto para falar do método, este artigo abordará algumas delimitações teóricas que realizamos para tentar responder essa questão, assumindo a concepção de currículo da pedagogia histórico crítica. Assim, iniciaremos com uma abordagem sobre a Educação Ambiental e, na sequência, aprofundaremos outras categorias próprias da Pedagogia Histórico Crítica.

\section{O Conteúdo da Educação Ambiental Crítica: Delineando a Questão}

Apesar de, inicialmente, no Brasil, ter se procurado construir uma definição universal para a EA, atualmente, com avanços do campo e da pesquisa sobre ele, sabemos que há uma diversidade de perspectivas, concepções e tendências. Sobre essa diversidade, que pode ser vista a partir de vários recortes teórico-metodológicos, realizamos uma caracterização em Souza e Salvi (2012), mas entendemos que Layrargues (2012) e Layragues e Lima (2014) nos apresentam uma categorização que permite compreender de maneira geral essas identidades diversas, a partir do que denominaram de macrotendências de Educação Ambiental.

Não é nosso objetivo tratar das macrotendências, pois o GPEA-UNESP, de partida, assume como referencial teórico-metodológico a perspectiva da EA crítica, pautada no materialismo histórico-dialético. Todavia, cabe destacar a análise de Tozoni-Reis (2008a), que nos aponta que o consenso existente entre as diferentes concepções de educação ambiental crítica, isto é, aquelas que se subsidiam nas perspectivas fenomenológica, hermenêutica, histórico-dialética, gira em torno da necessidade da modificação do modelo de desenvolvimento social, a necessidade de superação da lógica antropocêntrica, isto numa abordagem histórica e política. Como delineia, 
Assim, a necessidade de modificação do modelo de desenvolvimento é consenso entre os educadores ambientais [críticos], mas as formas e propostas para sua viabilização se diferenciam. O importante é apontar a impossibilidade radical de modificações conjunturais em uma organização social que impossibilita, profunda e estruturalmente, a relação equilibrada, plena, do homem com a natureza. O caminho parece ser a superação da lógica antropocêntrica que implica a dominação da natureza pelos homens e dos homens pelos homens, em toda sua complexidade histórica (TOZONI-REIS, 2008a, p. 57).

Para a superação dessa lógica, antropocêntrica e predatória, se faz necessária uma formação humana que possibilite a compreensão e o questionamento do que está posto na nossa sociedade; que fomente a assunção de posturas e ações no sentido de sua transformação, e, para alcançar esse projeto social, a EA desempenha um importante papel.

Como são diversas as propostas teóricas e educacionais em torno da EA, configurando atualmente um campo social de disputas (LAYRARGUES; LIMA, 2011), falar do campo da Educação Ambiental Crítica é igualmente falar de uma diversidade de abordagens em que o sentido de crítico pode ser influenciado por diferentes referenciais teórico-metodológicos. Nesse sentido, coadunamos com as discussões realizadas por Agudo e Teixeira (2020), que nos apresentam a importância de, apesar de valorizar a pluralidade de ideias, é fundamental demarcar o sentido de crítico a partir do referencial do materialismo histórico-dialético, entendendo a pedagogia histórico-critica como caminho possível para a construção da Educação Ambiental Crítica.

Dessa forma, a EA crítica é entendida como uma crítica à educação moderna que procura formar os sujeitos para a adaptação e reprodução da sociedade moderna. Assim, o projeto educacional que se coloca à EA necessita considerar a formação de sujeitos históricos, ou seja, sujeitos atuantes e conscientes de seu papel social, levando em conta a necessidade de posturas individuais e coletivas voltadas para a construção da sustentabilidade, em que se visa a formação de sujeitos capazes de conhecer e transformar o quadro societário atual.

A EA crítica pode ser compreendida como perspectiva educativa que traz, como eixo, uma proposta transformadora com relação à organização social e aos fundamentos que sustentam a relação sociedade-natureza. Dentre outras questões, traz discussões epistemológicas no que diz respeito à ciência moderna e suas formas de conceber a relação sociedade-natureza, acenando para a necessidade de se acrescentar uma visão histórica sobre a crise ambiental às propostas e ações educativas. É uma educação problematizadora, política, 
apoiada na práxis, com intuito de mobilização e participação para a gestão ambiental em prol da sustentabilidade ambiental (TOZONI-REIS, 2008a).

A EA crítica não deve ser ingênua quanto à educação como garantia da transformação ambiental, pois o conhecimento sobre as questões ambientais, ou mesmo uma reflexão crítica sobre estas, não são suficientes; são necessárias condições objetivas para que a transformação ocorra, e estas condições devem ser construídas em outros âmbitos da sociedade; portanto, o projeto para as mudanças desejadas deve existir para além dos muros da escola, para além do âmbito educacional, devendo atingir todos os setores sociais.

Demarcada a concepção de educação aqui assumida, questiona-se: O conteúdo da EA crítica é uma questão posta?

Já em um dos primeiros eventos realizados na década de 1970, na Conferência Intergovernamental de Tiblisi (1977), foram produzidas recomendações para a construção da EA, e a questão do conteúdo e sua metodologia aparecem de forma explícita, destacando-se principalmente a questão da interdisciplinaridade enquanto princípio metodológico cujo conteúdo envolve o tratamento das questões ambientais em suas diferentes dimensões: naturais, sociais, políticas e econômicas, considerando-se a relação local e global.

Embora passados mais de 40 anos desse evento, tratar a questão ambiental, envolvendo os aspectos naturais e sociais, considerando a EA numa perspectiva integradora e vinculandoa à realidade, são preocupações atuais.

Há um constante trabalho, por parte de educadores e pesquisadores, para o delineamento das dimensões que envolvem as ações humanas em relação à natureza, os conhecimentos necessários para sua compreensão, assim como os objetivos, finalidades e perspectivas metodológicas que devem orientar as práticas educativas ambientais, havendo uma diversidade de expressões e delineamentos nas diferentes expressões/posições político-pedagógico de EA no Brasil (LAYRARGUES, 2004; TOZONI-REIS, 2008a,b) e em outras partes do mundo (SAUVÉ, 2005).

O movimento predominante que observamos no campo da EA, no Brasil, nos últimos anos, se concentrou na defesa de princípios como a interdisciplinaridade, não havendo muita centralidade na questão de qual é o conteúdo da/para a EA. Conforme abordamos em TozoniReis et al. (2015), nesse âmbito a interdisciplinaridade passou a ser praticamente um dogma para os educadores ambientais. Isto não tem contribuído para a inserção escolar da EA crítica, visto que dificulta-se o aprofundamento sobre as formas de sua inserção, não se focalizando a 
questão do seu conteúdo, mas nas formas de sua realização, principalmente por meio de projetos ditos interdisciplinares, o que acaba por fortalecer sua presença periférica no currículo escolar. Nesse contexto, destacamos que a

(...) interdisciplinaridade é um meio e não um fim, ou seja, argumentamos no sentido da busca pela construção do trabalho educativo que viabilize a formação para a emancipação dos sujeitos e não no perseguir, como finalidade, a abordagem interdisciplinar que, na verdade, seria decorrente de um projeto formativo delineado (p. 66).

Adicional aos princípios metodológicos, precisamos refletir sobre quais os conhecimentos da/para a EA crítica? Como se estruturam? Como podem contribuir para a compreensão da realidade ambiental e da transformação deste cenário de crise? Como o processo da produção destes conhecimentos deve ser compreendido e ensinado? Em concordância com afirma Saviani (2010), adicionamos a essas perguntas às reflexões sobre por que e para que ensinar, assim como a quem se dirige o ensino.

De acordo com a autora, no campo do ensino, diferentes são as posturas frente ao conteúdo:

[...] ora valorizado como fim em si mesmo, acima do método, ora subordinado à relação professor-aluno, às técnicas, aos procedimentos, aos recursos didáticos; em alguns casos desacreditado ou aceito tão somente quando a serviço da conscientização; em outros, como fator de instrumentalização para fins de participação social (SAVIANI, 2010, p. 3).

A perspectiva de EA crítica que adotamos é coerente com a concepção de conteúdo "como fator de instrumentalização para fins de participação social", contemplado pela autora e presente no excerto acima. A adoção dessa perspectiva encontra suporte em Saviani (2011), Loureiro (2007), e Duarte et al. (2012) e, também, na problematização trazida por Freire (1980, 1987, 1997) que, mesmo não centrada na educação escolar, caracteriza a importância da formação humana pela via da conscientização crítica, para que haja uma inserção social crítica.

$\mathrm{Na}$ perspectiva da educação ambiental crítica, transformadora e emancipatória, os temas ambientais não podem ser conteúdos curriculares no sentido que a pedagogia tradicional trata os conteúdos de ensino: conhecimentos pré-estabelecidos que devem ser transmitidos de quem sabe (o educador) para quem não sabe (o educando). A educação crítica e transformadora exige um tratamento mais vivo e dinâmico dos conhecimentos, que não podem ser transmitidos de um polo a outro do processo, mas apropriados, construídos, de forma dinâmica, coletiva, cooperativa, contínua, interdisciplinar, democrática e participativa, pois somente assim pode contribuir para o processo de conscientização dos sujeitos para uma prática social emancipatória, condição para a construção de sociedades sustentáveis. Para superar o caráter informativo em busca de uma 
educação preocupada com a formação do sujeito ecológico, os temas ambientais, locais - significativos, têm que ser tomados como ponto de partida para análises críticas da realidade socioambiental (TOZONI-REIS, 2006a).

Como se percebe, uma das formas de pensar o conteúdo, no campo da EA, é por meio da chamada tematização do ambiente, que inicialmente busca aportes na perspectiva metodológica dos temas geradores de Paulo Freire, educador e teórico fundamental para pensarmos essa abordagem metodológica na educação ambiental crítica.

[...] uma pedagogia crítica da educação ambiental fundamentada no pensamento de Paulo Freire dá ênfase no conhecimento das relações sociais de dominação que se realiza na sociedade desigual para, através do processo educativo dialógico, conscientizar os sujeitos para transformar estas relações de dominação. Neste sentido, é o pensamento de Paulo Freire que inspira o Tratado de Educação Ambiental para Sociedades Sustentáveis e Responsabilidade Global (FÓRUM INTERNACIONAL DAS ONGs, 1995): transformação social, conscientização, educação política, cooperação e diálogo. Os temas do Tratado são problematizadores para um processo de conscientização político e transformador como a pobreza, a degradação humana e ambiental, a violência, a compreensão das formas de vida da população, suas condições de saúde, a fome e, em especial, a democracia (TOZONI-REIS, 2007, p. 12).

Além desse autor, no campo das pedagogias críticas, há especificidades educativas nas perspectivas teóricas. Assim, optamos pela Pedagogia Histórico-Critica, não nos afastando do sentido da tematização do ambiente, enquanto tema gerador na educação, mas o ressignificando nessa teoria pedagógica, em que as temáticas ambientais igualmente não são fins em si mesmos no processo educativo, mas meios, pois expressões da prática social, portanto como ponto de partida e de chegada, no processo de construção da consciência filosófica tão fundamental para a construção material da transformação dessa sociedade.

\section{A Pedagogia Histórico Crítica Como Fundamento Para a Inserção da EA Crítica na}

\section{Escola}

Como Saviani (2012) nos coloca, o objeto da educação escolar é a delimitação dos conteúdos essenciais a serem apropriados pelos indivíduos, e das formas mais adequadas de cumprir com esse objetivo educacional. Assim, ao pensarmos a Educação Ambiental Crítica, a partir e em diálogo com a Pedagogia Histórico-Critica, se coloca como central a necessidade da educação formal possibilitar a apropriação de conhecimentos que permitam os sujeitos se apropriarem do que a humanidade historicamente produziu e sistematizou. Sendo que, nessa perspectiva, o processo educativo tem uma intencionalidade clara e um compromisso político 
com a classe trabalhadora, no sentido de permitir que essa apropriação a permita compreender a sociedade desigual e exploratória, no sentido de ter instrumentos para a construção de sua transformação.

É, nesse contexto, que a pedagogia histórico-crítica, proposta por Dermeval Saviani e colaboradores, traz avanços qualitativos às discussões da EA crítica, uma vez que ambas assumem como princípio a realidade concreta que envolve os educandos (prática social), considerando as demandas e necessidades históricas dos sujeitos, no sentido de questionar a escola existente, situá-la num contexto mais amplo do que aquele das salas de aulas, e de valorizar o conteúdo como instrumento para compreensão e participação social, propondo alternativas e indicando a necessidade de uma educação que promova a práxis para a transformação social.

A concepção pedagógica da pedagogia histórico-crítica parte da prática social, e nisso se diferencia da pedagogia tradicional, que parte da preparação dos alunos de iniciativa do professor, e da pedagogia nova, que parte da atividade que é de iniciativa do estudante, centrando-se em conhecimentos que podem até ser universais, mas que não são necessariamente historicizados.

A prática social representa a totalidade social, que envolve professores e estudantes. No entanto, apesar de ser uma prática comum, estudantes e professores se encontram inseridos de maneira distintas, em que há níveis de compreensão diferentes sobre essa prática por esses dois agentes sociais. O professor possui uma compreensão sobre a prática social denominada de síntese precária, e a do estudante ainda é de caráter sincrético. O professor tem uma compreensão sintética, visto que, em sua prática pedagógica, realiza articulação de conhecimentos e experiências que obteve na prática social. No entanto, é precária a síntese, pois seu processo de inserção da prática social, em sua prática pedagógica, lhe exige que antecipe uma visão do que será possível ser feito com os estudantes, mas podendo apenas conhecer, de forma precária, o nível de compreensão deles. Já os estudantes têm uma visão sincrética, pois, por mais que tenham experiências e conhecimentos, sua condição de aluno implica a impossibilidade, no ponto de partida, da articulação da experiência na prática social que participam (SAVIANI, 2012).

Nesse sentido, utilizar como pressuposto a pedagogia histórico-critica, é reconhecer o papel central dos professores no processo de organização de conteúdos e proposição de mediações que permitam ao estudante sair de um nível de compreensão sincrético da prática social para um nível sintético. No entanto, até mesmo o professor, nesse processo educativo, 
elabora e reorganiza sua visão, e avança na síntese sobre a prática social, considerando que a totalidade que se configura é sempre contextual e histórica.

O ponto de partida do processo educativo é a prática social. Apesar de não ser uma questão de passos, Saviani (2012) apresenta outras etapas que fazem parte do processo pedagógico, que entendemos importante resumir na sequência.

Inicialmente o professor não irá apresentar novos conhecimentos, como se propõe a pedagogia tradicional, e nem um problema como um obstáculo que os estudantes precisam resolver, como na pedagogia nova. Cabe ao professor identificar os principais problemas colocados pela prática social e realizar um processo de problematização, o que exige pensar em quais problemas precisam ser resolvidos, no âmbito da prática social, e quais conhecimentos são necessários dominar para tanto. Nesse aspecto, a crítica de que a PHC é restrita e conteudista cai por terra, visto que esse processo de mediação que problematiza, dialoga com a realidade e ressignifica o próprio currículo prescrito, o que é intensificado nas etapas que se seguem.

Um próximo passo seria a instrumentalização, o que se difere da assimilação de conhecimento da pedagogia tradicional, ou da coleta de dados sobre a realidade da pedagogia nova. A instrumentalização é um processo ativo e dialético, em que se apropria dos instrumentos teóricos e práticos para equacionar os problemas detectados na prática social. Esses instrumentos são socialmente produzidos e historicamente preservados, assim a apropriação pelos alunos depende da atuação direta ou indireta do professor, que pode tanto apresentá-los diretamente ou indicar meios para que a transmissão ocorra.

O quarto passo é a catarse, que é a efetiva apropriação dos instrumentos culturais na consciência humana e que se tornam elementos ativos de transformação social, não é a generalização da pedagogia tradicional e nem a hipótese da pedagogia nova.

O quinto passo é o ponto de chegada do próprio processo educativo, a própria prática social, mas agora em outro nível de compreensão, esperando-se que os estudantes alcancem o nível sintético que o professor tinha como ponto de partida. O ponto de chegada não é a aplicação da pedagogia tradicional e nem a experimentação da pedagógica nova (SAVIANI, 2012).

Nessa compreensão do processo pedagógico e da clara intencionalidade da educação voltada "para a apropriação das camadas populares das ferramentas culturais necessárias à luta social que travam diuturnamente para se libertar das condições de exploração de que vivem" (SAVIANI, 2012, p. 71), defendemos uma concepção de currículo enquanto práxis. Isso não se 
caracteriza pelo entendimento do currículo como sendo tudo o que é realizado na escola, mas considera a sua dinâmica de desenvolvimento no contexto real da instituição escolar, numa articulação entre teoria e prática. Assim, concordamos com Saviani (2011, p.15), quando este define o currículo como o "conjunto das atividades nucleares" desenvolvidas pela escola, ou seja, não envolve todas as atividades realizadas na escola, mas aquelas consideradas essenciais por estarem vinculadas à socialização do saber sistematizado.

Conforme nos coloca Giardinetto (2010), os conteúdos essenciais aparecem na obra de Saviani, denominados por conteúdos clássicos. Tais conteúdos não se confundem como os conteúdos tradicionais, não se opõe ao moderno e nem o atual, mas aquilo que se fundou fundamental no contexto de produção de conhecimento ao longo do processo histórico da formação do gênero humano. Assim, assumir essa concepção, é entender que há conteúdos que contribuem de maneira mais efetiva na compreensão da prática social, e que o foco do processo educativo deve ser orientado por isso.

Gama e Duarte (2017) indicam alguns princípios que podem orientar a seleção dos conteúdos na concepção da PHC. Eles destacam três: a Relevância social do conteúdo; adequação às possibilidades sociocognitivas do aluno; e a objetividade e enfoque científico do conhecimento. Esses são princípios que se relacionam com os princípios metodológicos para o tratamento do conhecimento: da síncrese à síntese; simultaneidade dos conteúdos enquanto dados da realidade; ampliação da complexidade do conhecimento e provisoriedade e historicidade dos conhecimentos.

Tais princípios podem contribuir para a superação da superficialidade ou das dificuldades da demarcação dos conteúdos essenciais da educação ambiental, visto que muitas práticas realizadas na escola contribuem para o esvaziamento de conteúdo. É o que ocorre quando a escola privilegia os festejos de datas comemorativas em detrimento dos processos de ensino e aprendizagem de saberes sistematizados. Determinados conteúdos até podem estar associados a estas atividades comemorativas, mas estes não são essenciais e, sim, secundários, ao menos da forma com que são realizados, pois o foco é na atividade e envolvimento do estudante/comunidade e não no conteúdo. Nisso, não se propõe a seleção de conhecimentos que permitam compreender o cenário complexo das temáticas ambientais, muito menos se coloca no horizonte a necessidade de apropriá-los para questionar e transformar as relações sociais opressoras e degradadoras da natureza (TOZONI-REIS et al., 2015).

Há ainda uma limitação moralista, comportamentalista ou muitas das vezes de memorização de conhecimentos técnico-científicos, como bem caracterizado por Tozoni-Reis 
(2006b) , ao abordar sobre as concepções de educação ambiental predominantes na educação escolar. A EA escolar, em geral, tem um espaço de desenvolvimento predominante por meio de projetos, em datas como o dia da árvore, do meio ambiente ou da água, ou seja, sendo realizada de maneira pontual e totalmente desconectada de um projeto educacional e de princípios claros para a delimitação dos conteúdos curriculares.

É em contraposição a essas abordagens, que a concepção de EA crítica aqui defendida e que a sua inserção seja feita como parte do currículo, a partir da tematização do ambiente, no sentido de que esta venha a se constituir como atividade nuclear, sendo desenvolvida a partir de conteúdos essenciais para a compreensão do sujeito e de seu mundo, de sua relação com/na sociedade visando à formação humana capaz de superar a sociedade capitalista.

As temáticas ambientais, tais como água, lixo, unidades de conservação, mineração, perda da biodiversidade, dentre outras, de uma forma geral, poderiam orientar a construção de seu conteúdo quando localizada na prática social dos professores e estudantes.

A questão ambiental, numa perspectiva crítica, é uma formulação histórica recente do século XX, portanto, uma construção humana que procura colocar em debate as relações sociais localizadas em contextos específicos, seus reflexos na humanidade e no ambiente em que está inserida. É neste movimento de compreensão da questão ambiental, que se articula a reflexão sobre a necessidade de uma educação capaz de contribuir para uma formação dos sujeitos que os levem à compreensão de sua sociedade e ao enfretamento da crise atual. Assim, o campo da educação crítica incorpora o desafio de pensar formas de promover a formação para a superação do modo de vida exploratório da atual sociedade capitalista.

Cabe destacar que tais questões, enquanto temáticas ambientais, permitem uma compreensão da configuração histórica da organização social na relação sociedade e natureza, portanto, são expressões da prática social. Ao analisarmos a história da humanidade e sua relação com a natureza, identificamos valores e práticas sociais de exploração da sociedade sobre a natureza, mas do próprio ser humano pelo ser humano, o que influencia e faz parte do contexto da própria produção dos conhecimentos científicos.

No plano da prática social, as expressões dessa exploração se diferenciam, ao longo da história, e mesmo da classe social ou do grupo que se atua ou se faz parte, sendo que sua compreensão sofre influência das contradições sociais que interferem no direcionamento da educação escolar. Por exemplo, sabemos que a temática ambiental da água, sua escassez ou desperdício, aparece de forma distinta, e em proporções diferentes de uso e exploração, se compararmos o uso da água em um grande latifúndio com aquele presente na realidade das 
casas das periferias do país. Todavia, desconsiderando os interesses e contradições envolvidos, muitas das vezes, o que notamos na própria prática educativa ambiental é uma análise que coloca as responsabilidades e ações ao ser humano genérico, portanto a problemática da água é uma expressão do seu desperdício que é feito de igual impacto e responsabilidade independente da classe social envolvida e dos usos que dela são feitos nos diferentes espaços e dinâmicas de produção. Sabemos que essa última interpretação é coerente com uma perspectiva políticoideológica que trata a questão ambiental de maneira superficial, conservacionista ou pragmática, e que cria uma visão ilusória sobre a própria questão e consequentemente limita seu enfrentamento coletivo, conforme também caracteriza Layrargues (2012).

Ainda de acordo com o autor, decorrentes ainda de um histórico de educação ambiental conservacionista e pragmática no país, no processo educativo, muitas das vezes, a temática ambiental, seja qual for, é tomada em sua superficialidade, com recorte que beneficia determinada classe social para a manutenção do status quo. Contudo compreendemos que há que se estabelecer a complexidade, as múltiplas determinações envolvidas na configuração das temáticas, visto que elas não são categorias dadas e naturais do cotidiano, mas sofrem influências de diferentes visões de mundo e interesses em disputa que são localizados contextualmente.

Para reconhecer e conhecer alguma expressão social enquanto temática ambiental, há que se ter um processo de construção que é histórico, político e mesmo pedagógico, o que de forma consistente a Pedagogia Histórico-Crítica ajuda a construir. É, nesse sentido, que a assumimos como caminho teórico pedagógico para a educação ambiental crítica, em que as temáticas ambientais são colocadas no campo das práticas sociais.

Ao localizar a temática ambiental, no campo da prática social, é preciso compreender que a visão que se tem dela vai depender dos tipos e de quais relações são estabelecidas em sua compreensão, ou seja, essa visão pode estar mais próxima ou mais distante de uma compreensão concreta da realidade. Assim, no campo educativo, exige-se pensar nas mediações pedagógicas possíveis e necessárias.

Em suma, EA é educação e, na perspectiva crítica, tem que intensificar o enfrentamento do caráter autoritário, moralista, de transmissão mecânica de conteúdos pouco problematizadores e ingênua, no que diz respeito ao conflito de interesses nas sociedades modernas. A apropriação crítica de conhecimentos parte de uma concepção de ambiente mais complexa, que considera seu caráter social, histórico e dinâmico, superando dialeticamente a concepção biológica reducionista. Esta apropriação poderá garantir os espaços de construção e 
reelaboração de valores éticos para uma relação responsável dos sujeitos entre si e destes com o ambiente (TOZONI-REIS, 2006b).

\section{Considerações Finais}

Como podemos perceber, responder a questão, qual o conteúdo para a educação ambiental crítica, a partir da pedagogia histórico-crítica, não nos leva inicialmente a listar os conteúdos essenciais que serão selecionados mediante o trabalho pedagógico.

Antes de tudo, é assumir uma concepção teórico-metodológica pautada na concepção de realidade e de conhecimento do materialismo histórico-dialético, cuja leitura pressupõe a capacidade humana de construir uma compreensão concreta sobre a prática social. Ademais, é levar em consideração um olhar histórico sobre a relação sociedade-natureza, as contradições inerentes dessa relação e seu impacto na construção do conhecimento e na função social da escola. Tais questões não aprofundamos neste artigo, mas são elementos fundamentais que sustentam a concepção que buscamos construir.

\section{Referências}

AGUDO, M. M.; TEIXEIRA, L. A. A pedagogia histórico-crítica como caminho possível para uma educação ambiental crítica. Debates em Educação, Maceió, v. 12, n. 26, p. 283 $301,2020$.

DUARTE, N. et al. O Marxismo e a questão dos conteúdos escolares. In: SEMINÁRIO NACIONAL DE ESTUDOS E PESQUISAS "HISTÓRIA, SOCIEDADE E EDUCAÇÃO NO BRASIL”, 9., 2012, João Pessoa. Anais [...]. João Pessoa: Universidade Federal da Paraíba, 2012. v. 1, p. 3953-3979.

FREIRE, P. Educação como prática da Liberdade. 11. ed. Rio de Janeiro: Paz e Terra, 1980.

FREIRE, P. Pedagogia do oprimido. 17. ed. Rio de Janeiro: Paz e Terra, 1987.

FREIRE, P. Pedagogia da esperança: um reencontro com a pedagogia do oprimido. Notas de Ana Maria Araújo Freire. São Paulo: Paz e Terra, 1997.

GAMA, C. N.; DUARTE, N. Concepção de currículo em Dermeval Saviani e suas relações com a categoria marxista de liberdade. Interface (Botucatu), Botucatu, v. 21, n. 62, p. 521$530,2017$.

GIARDINETTO, J. R. B. O conceito de saber escolar "Clássico" em Dermeval Saviani: implicações para a Educação Matemática. Boletim de Educação Matemática, Rio Claro, v. 23, n. 36, p. 753-773, 2010.

LAYRARGUES, P. P. Identidades da educação ambiental brasileira. Brasília: Ministério do Meio Ambiente, Diretoria de Educação Ambienta, 2004. 
LAYRARGUES, P. P. Para onde vai a educação ambiental? O cenário político-ideológico da educação ambiental brasileira e os desafios de uma agenda política crítica contra hegemônica. Revista Contemporânea de Educação, Rio de Janeiro, v. 7, n. 14, p. 398-421, 2012.

LAYRARGUES, P. P.; LIMA, G. F. C. Mapeando as macrotendências político-pedagógicas da educação ambiental contemporânea no Brasil. In: ENCONTRO "PESQUISA EM EDUCAÇÃO AMBIENTAL", 6., 2011, Ribeirão Preto, 2011. Anais [...]. Ribeirão Preto: USP, 2011. p. 1-15.

LAYRARGUES, P. P.; LIMA, G. F. C. As macrotendências político-pedagógicas da educação ambiental brasileira. Ambiente \& Sociedade, São Paulo, v. 17, n. 1, p. 23-40, 2014.

LOUREIRO, F. B. C. Pensamento crítico, tradição marxista e a questão ambiental: ampliando os debates. In: LOUREIRO, F. B. C. (org.) A questão ambiental no pensamento crítico: Natureza, Trabalho e Educação. Rio de Janeiro: Quartet, 2007. p. 13-67.

SAUVÉ, L. Educação ambiental: possibilidades e limitações. Educação e Pesquisa, São Paulo, v. 31, n. 2, p. 317-322, 2005.

SAVIANI, D. Escola e Democracia. 42a ed. Campinas: Editores Associados, 2012.

SAVIANI, D. Pedagogia histórico-crítica: primeiras aproximações. 11. ed. Campinas: Editores associados, 2011.

SAVIANI, N. Saber escolar, currículo e didática: problemas da unidade conteúdo/método no processo pedagógico. 6. ed. Campinas: Autores Associados, 2010.

SOUZA, D. C.; SALVI, R. F. A pesquisa em educação ambiental: um panorama sobre sua construção. Ensaio, Pesquisa em Educação em Ciências, Belo Horizonte, v. 14, n. 3, p. 111 $129,2012$.

TOZONI-REIS, M. F. C. Temas ambientais como "temas geradores": contribuições para uma metodologia educativa ambiental crítica, transformadora e emancipatória. Educar em

Revista, Curitiba, n. 27, p. 93-110, 2006a.

TOZONI-REIS, M. F. C. (Re)Pensando a educação ambiental. In: TOZONI-REIS, M. F. C. Metodologias aplicadas à educação ambiental. São Paulo: IESDE, 2006b. p. 7-14.

TOZONI-REIS, M. F. C. Fundamentos teóricos para uma pedagogia crítica da educação ambiental: algumas contribuições. In: REUNIÃO ANUAL DA ANPED, 30., 2007, Caxambu. Anais Eletrônicos [...]. Caxambu: Associação Nacional de Pós-Graduação e Pesquisa em Educação-ANPEd, 2007. Disponível em:

http://www.anped.org.br/reunioes/30ra/trabalhos/GT22-3311-Res.pdf. Acesso em: 5 abr. 2020 .

TOZONI-REIS, M. F. C. A pesquisa-ação-participativa em educação ambiental como práxis investigativa e educativa. 2008. $169 \mathrm{f}$. Tese (Livre-docência) - Instituto de Biociências, Universidade Estadual Paulista, Botucatu, 2008a.

TOZONI-REIS, M. F. C. Educação ambiental: natureza, razão e história. 2. ed. Campinas: Autores associados, 2008b.

TOZONI-REIS, M. F. C. et al. A inserção da educação ambiental na Educação Básica: que fontes de informação os professores utilizam para sua formação? Ciência \& Educação, Bauru, v. 19, p. 359-377, 2013. 
TOZONI-REIS, M. F. C. et al. A educação ambiental histórico-crítica: uma construção coletiva. In: CONGRESSO DA PEDAGOGIA HISTÓRICO CRÍTICA: EDUCAÇÃO E DESENVOLVIMENTO HUMANO, 2015, Bauru. Anais [...]. Bauru: Faculdade de Ciências, 2015. p. 63-70.

\title{
CRITICAL ENVIRONMENTAL EDUCATION AND HISTORICAL-CRITICAL PEDAGOGY: REFLECTIONS FROM GRUPO DE PESQUISA EM EDUCAÇÃO AMBIENTAL/ GPEA - UNESP
}

\begin{abstract}
In view of the concern with the insertion of critical environmental education in school, we seek theoretical-methodological contributions in critical historical pedagogy. In this sense, this article will address theoretical reflections that are born within the "Grupo de Pesquisa em Educação Ambiental" - Unesp-Bauru and that were issued during the 1st Symposium on Dialectical Historical Materialism and Research on Science Education and Environmental Education. Thus, we approach the question of the content of critical environmental education from the curriculum design of critical historical pedagogy. Despite the question of the content and form of Environmental Education being present since its origins, we understand that the indepth debate on what should be its content in the school context is still absent. In this sense, assuming the school insertion of critical Environmental Education as the core of the curriculum is a way to overcome its limitations in theory and practice for the human formation necessary for social transformation.
\end{abstract}

Keywords: Essential contents; Curriculum; Environmental themes; Humanization

\section{EDUCACIÓN AMBIENTAL CRÍTICA Y PEDAGOGÍA HISTÓRICO-CRÍTICA: REFLEXIONES DEL GRUPO DE PESQUISA EM EDUCAÇÃO AMBIENTAL/ GPEA - UNESP}

\begin{abstract}
Resumem
Ante la preocupación por la inserción de la educación ambiental crítica en la escuela, buscamos aportes teórico-metodológicos en la pedagogía histórica crítica. En este sentido, este artículo abordará reflexiones teóricas que nacen dentro del "Grupo de Pesquisa em Educação Ambiental/GPEA- Unesp" y que fueron presentadas inicialmente durante el I Simposio de Materialismo Histórico Dialéctico e Investigación en Educación Científica y Educación Ambiental. Así, abordamos la cuestión del contenido de la educación ambiental crítica desde el diseño curricular de la pedagogía histórica crítica. A pesar de que la cuestión del contenido y la forma de la Educación Ambiental sean presentes desde sus orígenes, entendemos que el debate en profundidad sobre cuál debe ser su contenido en el contexto escolar aún está ausente. En este sentido, asumir la inserción escolar de la Educación Ambiental crítica como actividad medular del currículo, a partir de contenidos esenciales, es una vía para superar sus limitaciones teóricas y prácticas para la formación humana necesaria para la transformación social.
\end{abstract}

Palabras-claves: Contenidos esenciales; Plan de estudios; Temas ambientales; Humanización. 
Agradecimentos: Agradeço a todos os membros do Grupo de Pesquisa em Educação Ambiental, Unesp - Bauru, com os quais convivo desde o ano de 2010, cujas contribuições na minha formação são inestimáveis. 